\title{
Joanna Ebenstein's morbid obsession
}

Previously published at www.cmaj.ca

$\mathrm{S}$ he takes photographs of objects on the blurred historical boundaries between art and medicine. They're pictures of anatomical models, of skeletal remains, of pickled body parts. She has assembled a travelling exhibition of her work called Anatomical Theatre: Depictions of the Body, Disease, and Death in Medical Museums of the Western World and maintains a blog called Morbid Anatomy: Surveying the Interstices of Art and Medicine, Death and Culture. Joanna Ebenstein has been called dead-stuff obsessed. But it's far more complicated than that.

"These artifacts are as much about culture as they are about the human body," says the 38-year-old, Brooklyn, New York-based graphic designer, photographer and cultural historian. "I didn't want them to be viewed as pure spectacle, although there's always that element when the human body is displayed. What I wanted was for people to see them as historical and art objects that should be treasured and preserved as things that can tell us more about the past."

Ebenstein's fascination began in her childhood; her grandfather was a physician and her father was an amateur naturalist who kept her supplied with formaldehyde so she could preserve the dead animals she found. "I don't love dead things as such, but I see the beauty in them," she says.

Growing up, Ebenstein considered becoming a biologist, but instead pursued a degree in intellectual history, then launched a career as a graphic designer.

However, her childhood fascination with the natural sciences kept asserting itself. Finally, two items she stumbled upon conspired to send her down her current path of inquiry. One was a calendar of anatomical specimens put out by the Mütter Museum of the College of Physi-

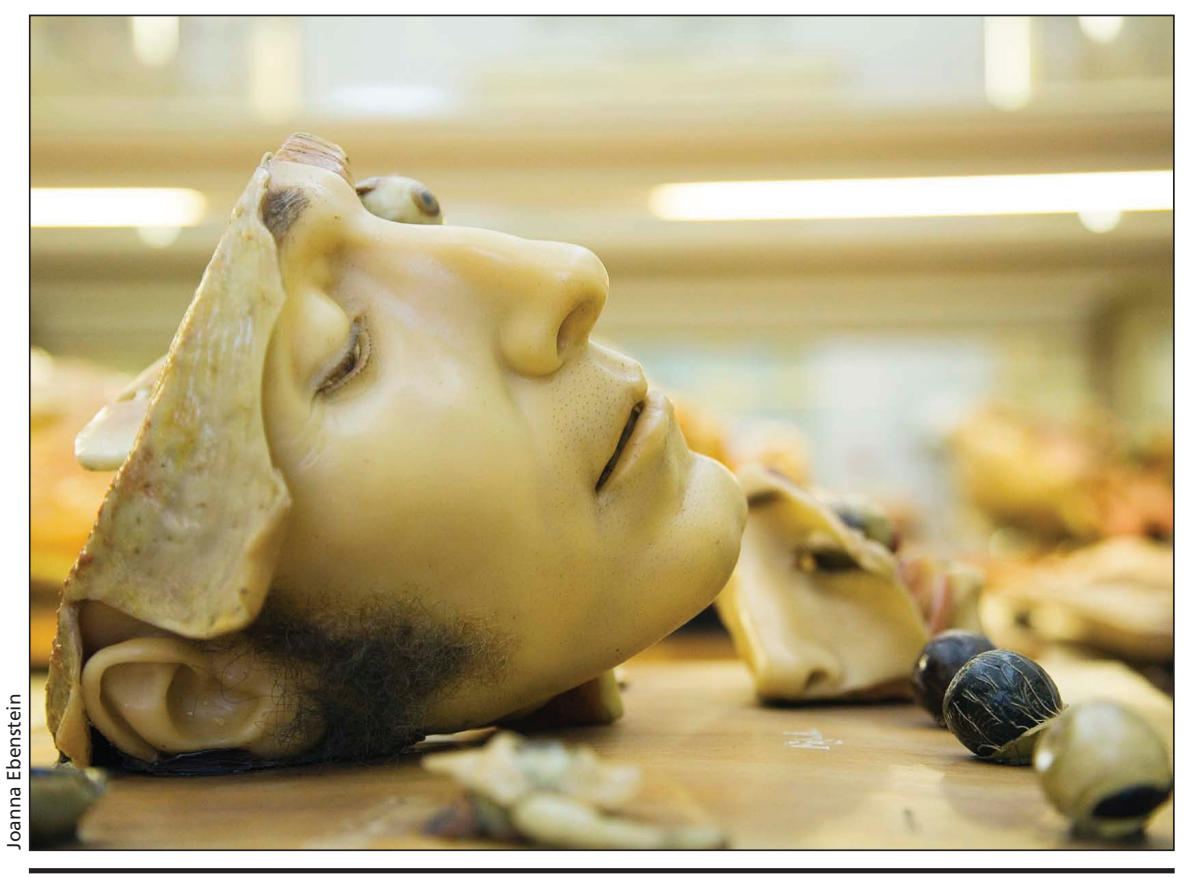

This wax model of the eye apparatus and related structures by Clemente Susini in the late 18th or early 19th century, was photographed at the Museum of Anatomical Waxes, Bologna, Italy.

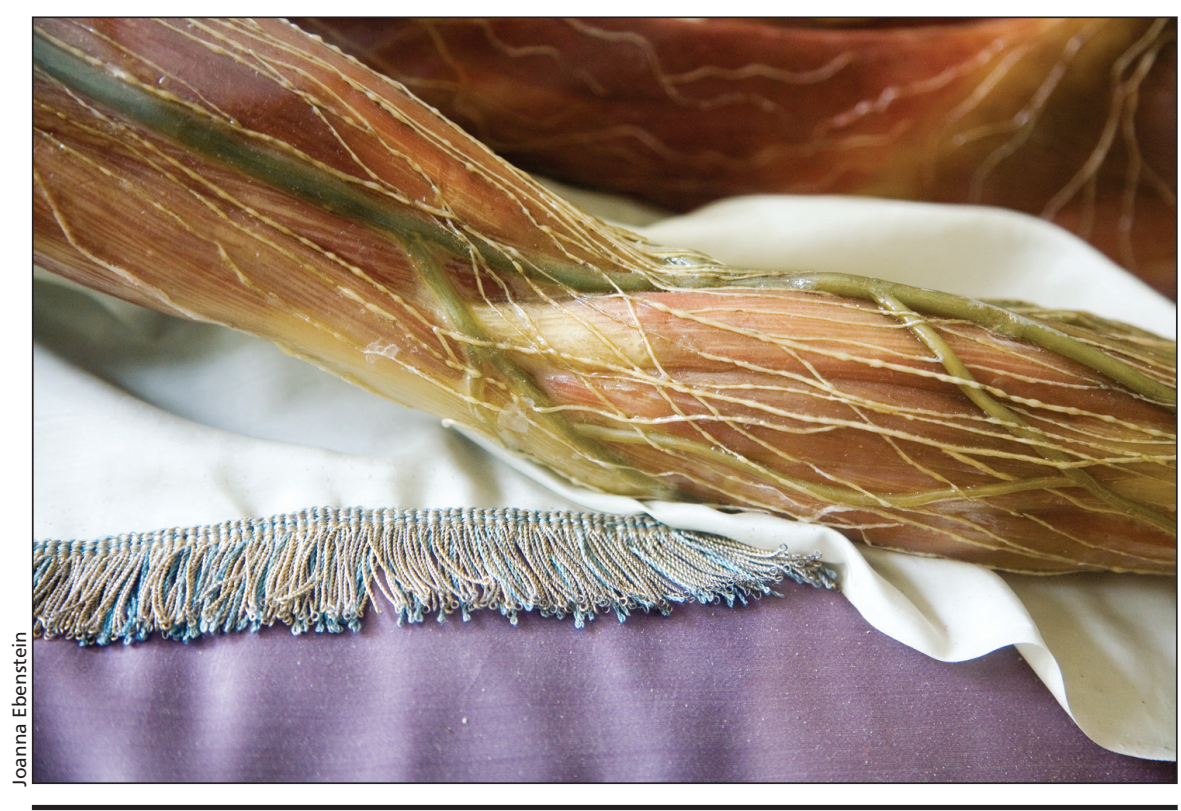

This is a detail of the "Statue of a Young Man Showing the Course of the Arteries" at the Museum of Natural History of Florence, Italy. The wax model was probably modelled by Clemente Susini around 1790. 


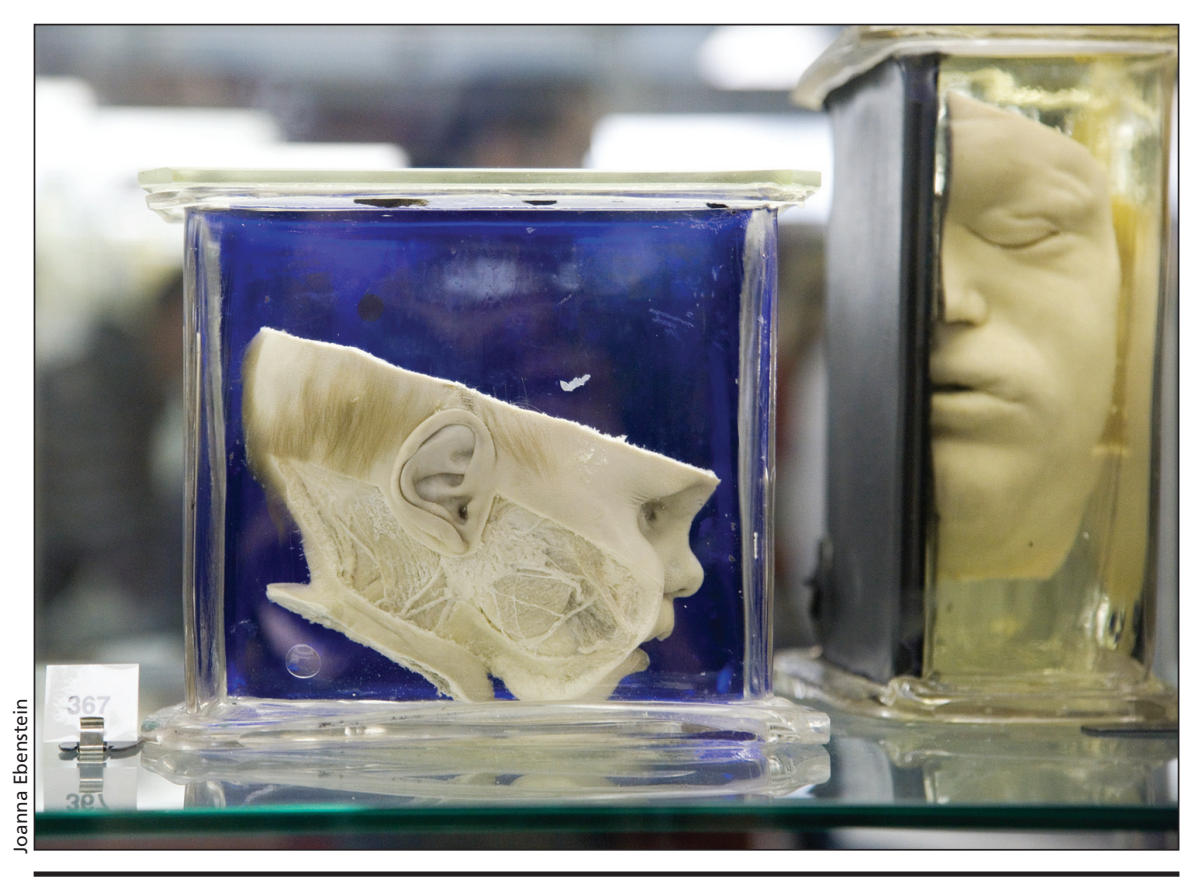

An artful presentation of 20th-century anatomical preparations at the Vrolik Museum, Amsterdam, the Netherlands.

cians in Philadelphia, Pennsylvania. The other was a 2001 book by Stephen T. Asma, Stuffed Animals and Pickled Heads: The Culture and Evolution of Natural History Museums.

In 2007, without knowing exactly where it would take her, she embarked on a pilgrimage to some of the leading medical museums in the United States and Europe, where she took thousands of photographs of anatomical artifacts.

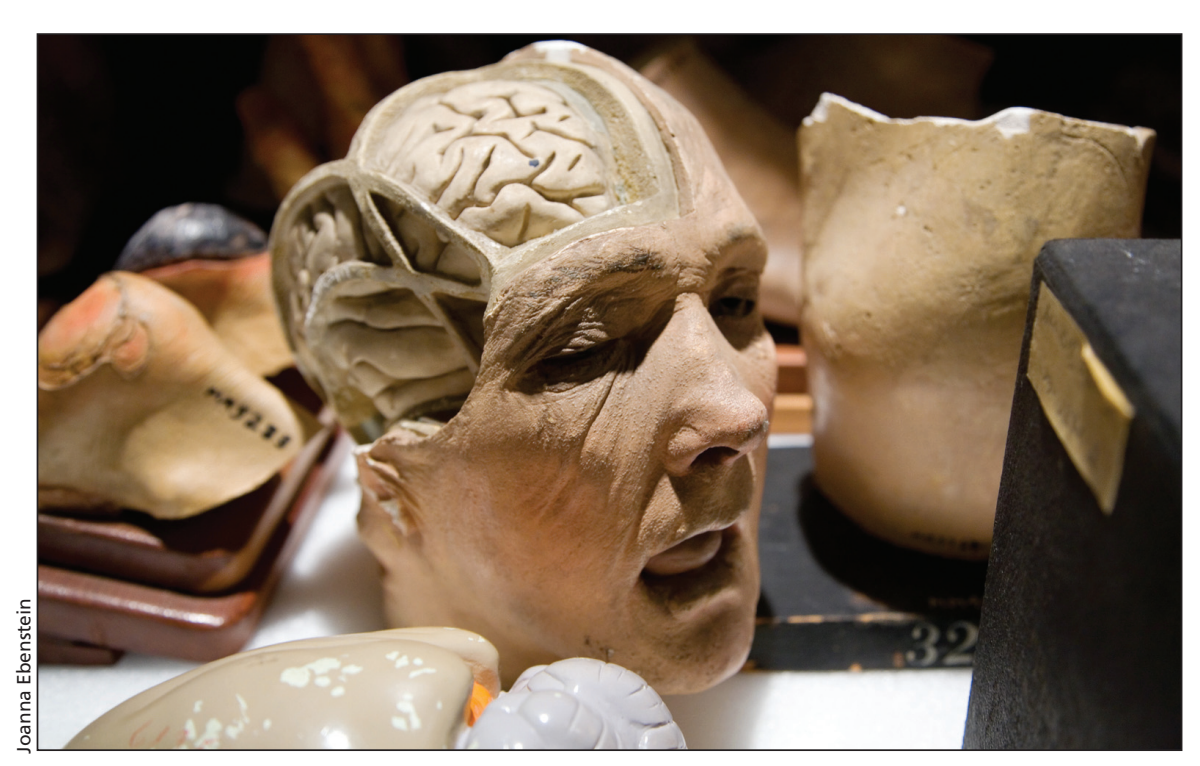

These assorted anatomical models were found in a drawer in a back room of the National Museum of Health and Medicine, Washington, DC.
"I called it 'The Project,' but I didn't know what it was," she says. "I just had a feeling I'd know what to do with the photos when the time came."

Ultimately, "The Project" evolved into Anatomical Theatre, an exhibition intended to help rescue anatomical artifacts from the dustbin of history by reframing them as artist or artisan-created objects rather than as scientific relics. 


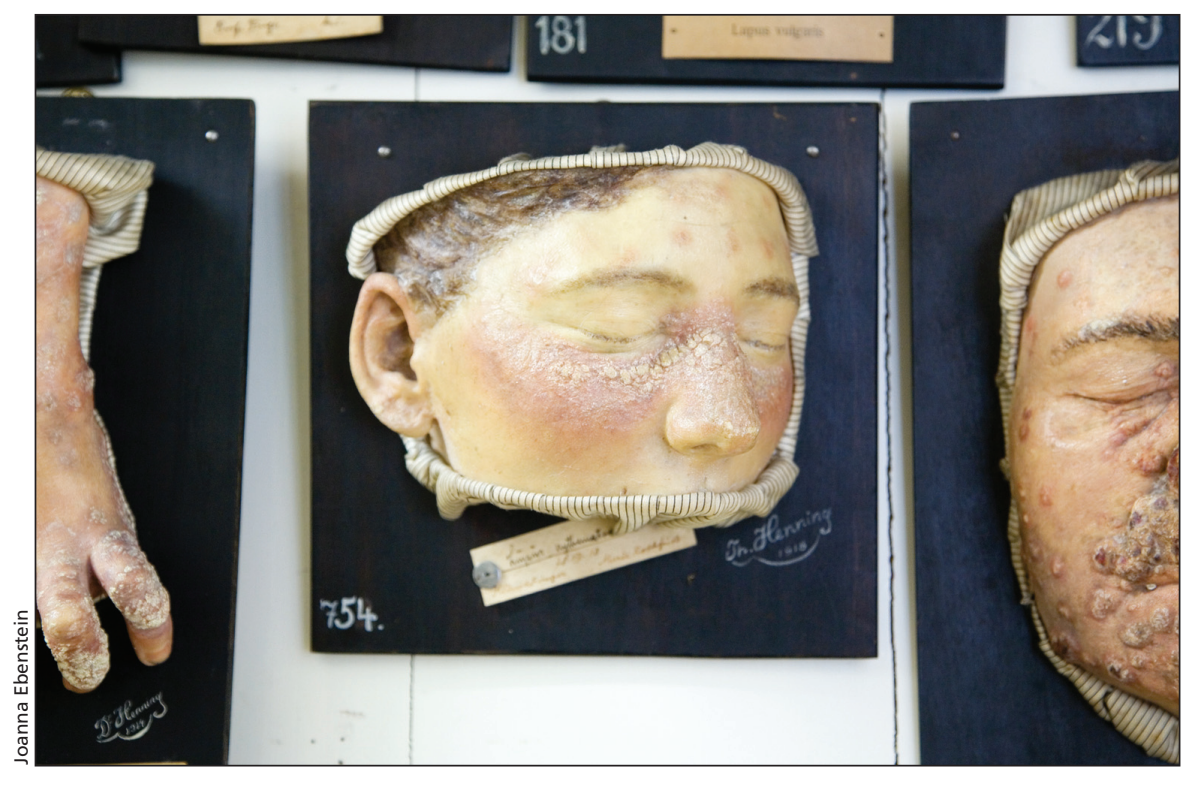

These wax moulages, probably made by Carl Henning (1860-1917) or Theodor Henning (1897-1946) were photographed at the Museum of Pathological Anatomy, Vienna, Austria.

A compulsive collector of objects and images herself, Ebenstein is fascinated by what lurks behind the acquisitional impulse. "Collecting is kind of pathology in itself," she says. "There's a certain psychology about it that's not pretty. And I imagine there's something you have to reconcile when, as a doctor, you want to collect this amazing speci-

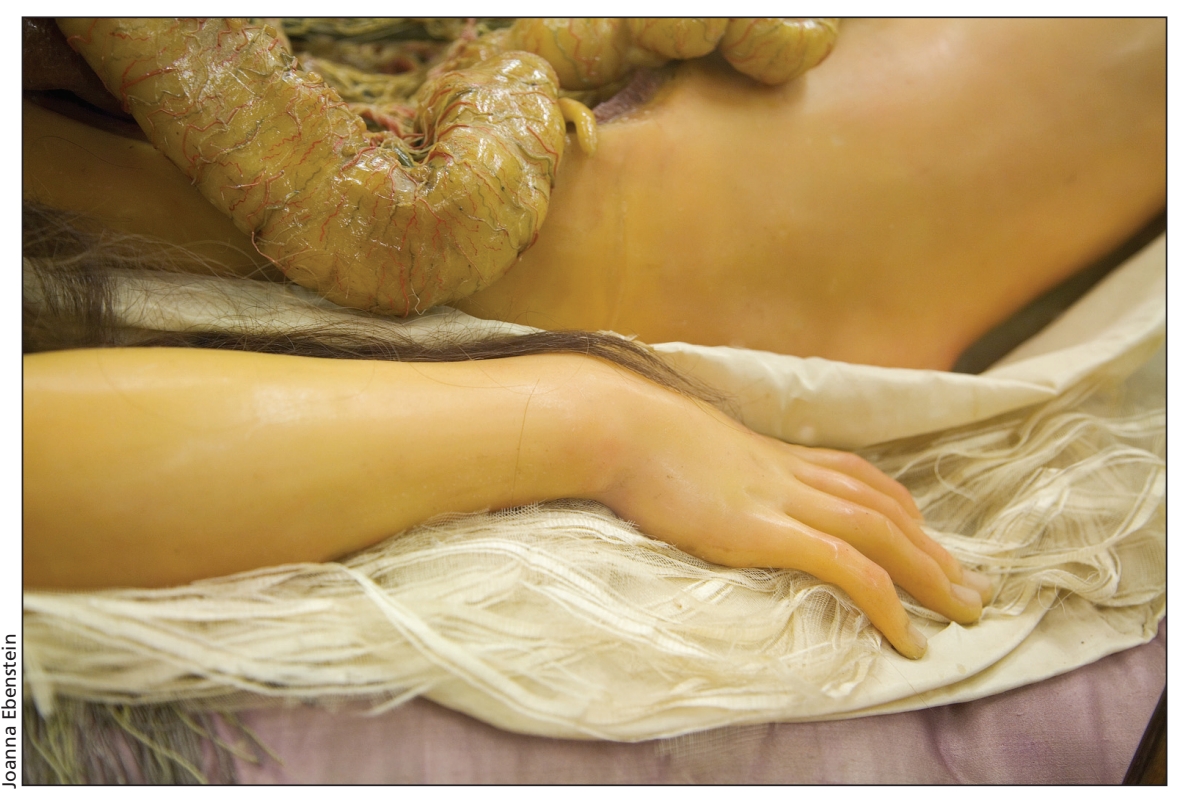

A detail from "The Slashed Beauty," a wax model with human hair in the Museum of Natural History in Florence, Italy. It was probably modelled by Clemente Susini around 1790. waxes. Even the things in formalin or formaldehyde require constant upkeep. So people are really worried that a lot of these collections that are still intact might decay. And that's one thing I really wanted to do with [the blog] Morbid Anatomy is try to bring some attention to these artifacts and raise appreciation of them."

In that, she has had some success. The website has proved unexpectedly popular. So too has her travelling exhibit, Anatomical Theatre, which opened at the University of Alabama's Museum of Health Sciences in Tuscaloosa in the fall of 2007. Then there was a follow-up show, The Morbid Anatomy Gallery: Gallery as Wunderkammer, featuring her photographs of privately held collections in the United States.

She has also been organizing a series of presentations under the umbrella "Morbid Anatomy Presents" at the Observatory Gallery, Brooklyn, New York. One of the latest was "Bodies Embalmed by Us NEVER TURN BLACK!": A Brief History of the Hyperstimulated Human Corpse." To her surprise, the evenings have attracted capacity audiences.

In addition to all of this, Ebenstein has created a small Morbid Anatomy Library housed at the Proteus Gowanus Interdisciplinary Gallery and Reading Room near her Brooklyn home. Here, members of the public can, by appointment, spend some time with the many books and artifacts, ranging from miniatures of death masks to skulls, photos of people in coffins to stuffed animals, that she has been collecting since she was 17 .

"There's a real interest," she says. "You know, I've liked things like this all of my life and I've never felt part of a community of people who also liked it as much as I do now. It's amazing to me."

\section{David McDonald}

Writer and filmmaker

Ottawa, Ont.

David McDonald's most recent documentary, Cereal Thriller, is about the unintended consequences of a 1955 cereal-box promotion. 